\title{
Da Conceituação de Estado Subjetivo até a Proposição dos Escalôes de Percepto
}

\author{
Arno Engelmann ${ }^{1}$ \\ Universidade de São Paulo
}

\begin{abstract}
Resumo
O artigo refaz o percurso de Engelmann, lidando em 1962 com perceptos chamados de afetivos até a proposição mais recente de escalões de percepto. O estudo aprofundado dos perceptos afetivos indicavam estados conscientes internos, porém não localizados. Engelmann denominou-os estados subjetivos. Mas deparou que havia ao mesmo tempo outros perceptos internos, esses localizados. A solução era dois escalões: um superior — estados subjetivos — e outro inferior — perceptos internos. Mais tarde Engelmann encontrou estados objetivos, estados conscientes não localizados e externos, representados principalmente por locuções meteorológicas. Finalmente, reestudando um número enorme de experimentos de percepção humana, verificou que havia cinco escalões de percepto, organizados prioritariamente na seqüência seguinte levando em conta o tamanho das partes: estados total, bipartido, supramodal, modal e fragmentário. Os indivíduos são capazes de estar momentaneamente apenas num desses escalões, nunca mais de um. Não se sabe, por enquanto, se é possível representar por intermédio de escalões outras partes da consciência além dos perceptos.

Palauras-chave: Percepção; emoção; consciência; linguagem; teoria da gestalt.
\end{abstract}

From The Subjective State Concept toward The Percept Echelons Proposal

\begin{abstract}
Dealing firstly with the affective percepts in 1962 and ending with percept echelons, the paper reconstructs Engelmann's psychological pathway. A serious study of mostly affect percepts indicated nonlocalized internal conscious states. Engelmann called them subjeticve states. But at the same time he found that there were other internal but localized external percepts. He called them objetive states. They were mainly characterized through reporting the weather. Finally, revising numerous perception studies, total, bipartite, supramodal, modal and fragmentary states are found and organizaed through largeness priority. Engelmann called them percepts echelons. In one moment only one percept echelon is possible, not more than one. So far it is not known if others parts of consciousness are divisible through echelons.

Keywords: Perception; emotion; consciousness; language; gestalt theory.
\end{abstract}

Em 1962 estava preocupado em que subdivisão da psicologia deveria colocar as minhas pesquisas sobre emoções. De acordo com o esquema experimental, iria utilizar os principais nomes de emoçôes apresentados a sujeitos como meio de chegar-se, por seu intermédio, a acontecimentos dentro das suas consciências. Evidentemente, não usei o termo consciência nas apresentações da época. Deveria investigar a maneira com que os ditos acontecimentos se relacionam entre si formando uma espécie de mapa. É baseado nesse mapa que os sujeitos experimentais iriam classificar os nomes de emoções por intermédio de escalas. O básico para mim era constituir o mapa. Como a pesquisa deveria ser feita com sujeitos morando no Brasil, é evidente que a primeira tarefa era

\footnotetext{
1 Endereço para correspondência: Rua da Consolação, 3617/ 42, 01416-001,
} São Paulo, SP. Fone/Fax: (11) 3088-8759. E-mail: aengelmann@attglobal.net colher uma lista portuguesa de emoções conhecidas pelos sujeitos.

$\mathrm{Na}$ época muitos colegas, sob influência do behaviorismo radical, achavam que meu estudo deveria constituir uma parte do comportamento verbal. Ainda que a parte de comportamento verbal era fundamental como instrumento de pesquisa, o cerne da questão se caracterizava por ter o objeto inicial aquilo que era relatado verbalmente, não os tipos de relatos verbais. Se alguma coisa pudesse ser dito a respeito do que era relatado verbalmente, era que se tratava de consciência. Era um relato de consciência da mesma maneira como eram relatos de consciência inúmeras respostas verbais em experimentos de percepção ou cognição humanas.

\section{O Conceito de Estado Subjetivo}

Em conversas comuns, as pessoas relatavam que sentiam uma determinada emoção. A utilização dos vocábulos que sentiam a emoção, que estavam numa 
emoção, que ficavam numa emoção, etc. parece caracterizar a consciência individual das emoções. Eram verbos semelhantes a perceber, porém havia algo de diferente. Por isso os empregavam.

Qual a diferença entre perceber e sentir? Percebo objetos, percebo pessoas, percebo cheiros, percebo o gosto da comida, percebo dores. Nessa percepção uma parte do ambiente ou uma parte de meu corpo é notada. Entretanto, quando sinto alegria, sinto raiva, fico apaixonado, esse sentir ou ficar refere-se a todo meu corpo, a todo meu organismo. E é também isso que ocorre com outras pessoas. A diferença reside em quanto vai ser notado. Quando uma parte do total é notada, fala-se na língua corrente em percepção. Quando a parte é bem maior ou quando é o todo, pode-se dizer que se fala em emoção. Entretanto, a parte notada por sujeitos será apenas diferente no uso natural dos dois verbos: partes pequenas seriam percebidas; partes maiores seriam sentidas, seriam sentidas enquanto uma determinada emoção.

A parte notada seria notada conscientemente. São fatos da minha consciência as diversas percepções e as diferentes emoções. E são fatos da consciência dos organismos as diversas percepções e emoções de outras pessoas. Há uma palavra pouco usada nas notações conscientes que corresponde a algo no ambiente ou no corpo: percepto (Ferreira, 1999; Prado e Silva, 1970). Percepção pode ser não consciente. Se for consciente então o melhor é chamála de percepto. Percepto é um termo que emprego nos últimos dez anos para caracterizar o tipo de conteúdo perceptivo da consciência. Entretanto, já era utilizado por Köhler (1938a).

Então, dever-se-ia falar em emoção toda vez que um indivíduo apresenta consciência no seu próprio corpo e essa consciência qualifica o corpo todo? Koffka (1935) chama de emoção consciente a dinâmica das forças psicológicas intra-ego. O ego é a parte da consciência ligada ao corpo da pessoa, restando a outra parte da consciência à porção externa. A explicação fenomenológica dos gestaltistas me influenciou fortemente.

Em 1963, li a parte das faculdades afetiva, volitiva e cognitiva de dois dicionários analógicos brasileiros e anotei os vocábulos que poderiam ser incluídos numa lista de emoções, mais tarde a ser dada a sujeitos (Azevedo, 1950; Spitzer, 1956). Os colegas em psicologia nessa época eram poucos, de maneira que a pesquisa foi exclusivamente minha. Havia na lista muitos termos que não se encaixavam na categoria de emoções. Vocábulos que nem intuito, vacilante, preguiça, intimidade são exemplos. Entretanto, casavam-se com sentir. Achava, e ainda acho atualmente, que vocábulos para o tipo de percepto seriam iguais a alegria, raiva e apaixonado. O percepto seria algo que ocuparia toda a parte interna do corpo, não havendo aí qualquer divisão, ao contrário dos perceptos comuns representadas no ambiente - caneta, cachorro - ou no próprio corpo - dor no incisivo superior direito, pressão no braço esquerdo. Portanto, ou deveria aumentar o conceito de emoção - chamando em psicologia termos de emocionais apesar de não corresponderem ao uso comum da palavra — ou introduzia um novo termo. É essa última solução que me pareceu a melhor.

Que há de comum entre os vários exemplos dados? Para mim, esse comum (1) é consciente, (2) refere-se à parte do corpo da pessoa, (3) a pessoa é incapaz de indicar mais nada em relação a esta localização anterior e (4) dura um certo tempo. Criei o termo estado subjetivo. Seria subjetivo por se referir à parte debaixo do percepto da pele do indivíduo. Seria estado porque dura sempre um certo tempo, ainda que esse tempo pode ser curto, médio ou longo (Engelmann, 1978).

Apresentei o novo conceito publicamente em 1972, na minha tese de doutoramento. Em 1978, saiu publicado. O curioso é que o título da publicação é Os estados subjetivos. Escrevo no livro:

Há outros tipos de relatos verbais que não podem ser acompanhados de apontar. São referidos verbalmente ao organismo sem especificação adicional. Não são localizados numa determinada região do corpo. Não possuem uma relação ponto a ponto com um "acontecimento" "no espaço — ainda que seja possível estabelecer uma sua relação com ocorrências precursoras. Propomos a expressão relatos verbais de estados subjetivos $^{3}$ para denotá-los e a de estado subjetivo para designar a ocorrência que dá origem a tais relatos...(Engelmann, 1978, pp. 77-78).

\section{Dois Níveis de Percepto, ou Melhor, Dois Escalões de Percepto}

Como deve ter ficado claro no uso do conceito de estado subjetivo, uma boa fração desse uso corresponde a emoções. Entretanto, em uma teoria importante sobre as emoções proposta por William James $(1884,1922$ / 1967), a consciência emocional era a totalidade dos perceptos resultantes das mudanças fisiológicas que ocorrem na situação excitadora. Apenas um ano depois, Carl Lange (1885, 1887, 1922/1967) expôs independentemente quase a mesma teoria de James. Seria esta teoria, a de James-Lange como é conhecida desde

\footnotetext{
${ }^{2}$ Mudei a palavra fenômeno no original por acontecimento. Fenômeno representa na minha atual teoria de duas consciências, apenas a parte da consciência imediata. Acontecimento é nome de qualquer parte do universo. Pode também ser a consciência de outros seres humanos (Engelmann, 1997a).

${ }^{3}$ A expressão relatos verbais de estados subjetivos está grifada no texto original.
} 
os fins do século XIX, suficiente para derrubar o que descrevi antes?

Os perceptos devidos a excitação do sistema nervoso autonômico aferente sem dúvida existem e existem principalmente no caso de emoções. Mas dizer que a consciência de emoção nada mais era do que o conjunto das percepções periféricas é um passo que vai além do necessário. Por que William James achava que a consciência da emoção era somente isso? Consultando a opinião dos neurologistas da época, James (1890/1950) julgava que não havia no cérebro centros emocionais. Hoje em dia a opinião dos neurologistas é bem diferente.

Claparède (1928), pelo contrário, acentuou a emoção como um acontecimento global. Reconhecendo a importância da teoria de James-Lange enquanto localização das emoções, Claparède achava, no entanto, que é a forma ou gestalt dos múltiplos perceptos orgânicos a origem da emoção, e não os meros perceptos.

Há uma série de estudos mais recentes que tocam sobre a importância de perceptos internos e sua relação eventual com emoções. Cito dois. Mason (1961) reuniu inúmeros estudos fisiológicos que constavam de periódicos e livros até 1958. Classificou-os em 28 áreas, baseadas em regiões da superfície do corpo para situálas, ainda que cada área é tridimensional e ocupava toda a sua porção interna. Além disso, incluiu algumas áreas amplas do corpo. O corpo é sempre integrado, diz Mason. Como resultado, chegou a uma série de estados psicológicos não-cognitivos. Entre os estados, havia alguns que eram julgados emocionais: alegria, amizade e amor, raiva, medo, depressão e nojo. Há outros, que não eram relacionados com a emoção: fadiga, fome e sede. E outros ainda cuja classificação emocional era duvidosa: sentimento sexual e tensão. Nieuwenhuyse, Offenberg e Frijda (1987) dividiram o corpo humano em 63 seções. Aplicando a pesquisa com 172 sujeitos, concluíram que há distinções para relacionar dez emoções na base dos perceptos localizados internos.

Os perceptos internos e os estados subjetivos são ambos perceptos e são perceptos que se referem à parte interna ou subjetiva. Em que se distinguem? Parecem ser dois níveis diferentes: o espaço ocupado pelo estado subjetivo é bem maior do que os espaços corporais internos. É um espaço que ocupa a totalidade do corpo percebido.

O que se entende por nivel? Nível é um ponto numa escala hierárquica. Porém nível é, além disso, um dos conceitos básicos na teoria geral de sistemas (J. G. Miller, 1978). Nessa teoria, cada nível é o ponto em que vários sistemas se reorganizam num supra-sistema ou sistema de ordem superior. Sistema é um conceito compreendido como um conjunto de unidades apresentando relações entre si. Na natureza há uma seqüência de sistemas. Quais os sistemas? Variam um pouco de autor para autor. Entre os sistemas minerais é possível citar: os átomos, as moléculas, os planetas, as estrelas, as galáxias, os aglomerados de galáxias, os superaglomerados de galáxias. Ou, levando-se em consideração ocorrências vivas é possível citar: as células, os órgãos, os organismos, os grupos, as organizações, as sociedades, o sistema supranacional, isto na classificação de James G. Miller em 1975 (Bertalanffy, 1968; Engelmann, 2001; Jantsch, 1980; J. G. Miller, 1978; J. G. Miller \& J. L. Miller, 1982; Rapoport, 1968).

Um nível superior, ainda que formado pela ação dos níveis imediatamente inferiores, apresenta uma estrutura realmente nova. Entretanto, as repartições das disciplinas caem por baixo. "A abordagem dos sistemas gerais é necessariamente interdisciplinar, até antidisciplinar ${ }^{4}$ " (J.G. Miller, 1978, p. 1045). Existe apenas o cientista empírico com diferenciação de objeto de estudo.

O biólogo Bertalanffy (1972/1975) apresentou as primeiras idéias sobre teoria geral de sistemas, oralmente em 1930 e mais tarde em diversas publicações posteriores à Segunda Grande Guerra. Os sistemas seriam holísticos. Bertalanffy reconheceu a anterioridade de Köhler (1920/ 1938b) e de Whitehead (1926/1985) em sua visão do universo (Bertalanffy, 1968, 1972/1975).

Köhler foi um psicólogo que, juntamente com Wertheimer e Koffka, originou a escola gestáltica em 1913. De acordo com a escola, em qualquer processo percebemse todos ou gestalten ${ }^{5}$. Cada gestalt é formada de partes. Entretanto, essas partes não funcionam como elementos. Uma gestalt é diferente de outra gestalt, ainda que uma gestalt possa ser formada de outras gestalten. "É todavia importante ... que os perceptos de objetos individuais eram gestalten e o percepto do relacionamento entre os diversos objetos individuais percebidos era também uma gestalt" (Engelmann, no prelo). Köhler ampliou a teoria da gestalt para o campo transfenomênico ${ }^{6}$. No entanto, no livro de 1920 reconhece a importância de Max Wertheimer, com sua teoria dos processos cerebrais que estariam na base do movimento aparente (Ash, 1995; Engelmann, no prelo; Köhler, 1920/1938b).

O sistema de Bertalanffy e a teoria da gestalt apresentam a mesma organização. A única diferença é que os níveis da teoria geral de sistemas superior introduzem gestalten mais

\footnotetext{
${ }^{4}$ Minha tradução da sentença de James Grier Miller.

${ }^{5}$ Gestalten é plural, gestalt é singular, e isto em alemão. É melhor usarmos também gestalten em português ao invés de falar em gestalts.

${ }^{6}$ Ainda que a teoria de Köhler se referisse ao campo físico naquele livro, o alargamento de sua abordagem é aquilo que chama de campo transfenomênico ou tudo que vai além dos fenômenos.
} 
bem organizadas do que as gestalten geralmente citadas. Fui aluno de Annita Cabral a partir de 1956. Reconheço a ela os meus primeiros passos na psicologia gestáltica. Continuo nessa linha, ainda que haja vários pormenores de outros pensadores que aceito, entre os quais os níveis de organização. Em 1982, saiu publicado pela primeira vez a minha adesão à teoria geral de sistemas (Engelmann, 1982).

Os psicólogos trabalham principalmente com o nível de organismo, nível do indivíduo animal. Sem dúvida, é importante para melhor compreensão de acontecimentos no organismo conhecer o nível imediatamente inferior. E, igualmente, é importante conhecer o nível imediatamente superior. Entretanto, a grande maioria das pesquisas psicológicas é organísmica.

Dentro do nível de organismo, pode-se estudar as consciências de outras pessoas ou consciências-mediatas-deoutros $^{7}$. As consciências-mediatas-de-outros são formadas, entre outras partes, por perceptos. Nos perceptos notam -se também dois níveis: um superior, que chamei de estado subjetivo, e um inferior, que seriam os perceptos internos localizados. Entretanto, esse uso da palavra nivel seria diferente da utilização da mesma palavra dentro da teoria geral dos sistemas, no qual atingir um nível seria dado quando surge uma estrutura realmente nova. Por essa razão procurei uma palavra diferente. Escalão é, no dicionário de Aurélio "Cada um dos pontos sucessivos de uma série" (Ferreira, 1986, p. 682). Escalōes seriam níveis, mas não na representação dos sistemas.

\section{O Conceito de Estado Objetivo}

Logicamente, se os estados subjetivos existem na consciência como perceptos ocupando cada um a parte interna, seria possível também estados objetivos existirem? Isto é, seriam perceptos ocupando cada um toda a parte externa, ao invés da interna? Pensei no problema. Realmente, diversas línguas possuem palavras que denotam tipos de tempo metereológico. Se o tempo é chuvoso, é quente, é gelado, diz-se usando apenas uma locução.

\footnotetext{
${ }^{7} \mathrm{Na}$ minha teoria da consciência há uma consciência-imediata e muitas consciências-mediatas. $\mathrm{O}$ conceito de consciência-imediata refere-se a tudo que é conhecido imediatamente por uma pessoa. Dura um momento. Observadores de fora da pessoa humana acham que essa duração é de mais ou menos 3 segundos. O conceito de consciência-mediata refere-se a uma parte dentro do organismo de seres humanos e, muito provavelmente, de outros animais. A consciência-mediata se divide em consciência-mediata-do-observador, que se alcança através da memória do observador, e consciência-mediata-de-outros, que se alcança através da percepção do corpo de outros animais, humanos ou não-humanos. A consciênciamediata-de-outros é a única dessas consciências a permitir estudos empíricos (Engelmann, 1997a, 1998, 2001).
}

E parece que utilizando a locução, quer se utilizar um percepto único, cuja única localização é no espaço de fora. Portanto, está-se diante de estados objetivos.

Num pequeno artigo, exemplifiquei estado objetivo como indicado por locuções como $O$ dia está luminoso, $O$ dia está quente, Está escuro, Sinto o dia triste (Engelmann, 1985). Apresentei, portanto, dois escalões: o superior, constituindo o estado objetivo-subjetivo, e o inferior, constituindo perceptos externos e internos.

Entretanto, nesses perceptos inferiores, o sentido ou a modalidade seria necessariamente visual, gustativa, de pressão, etc. ou haveria um lugar também para um aristotélico sensocomum? Teria um lugar para as sensações que foram realmente percebidas por um grupo grande de sujeitos, principalmente no grupo experimental de Titchener? E, de outro lado, seria possível um estado que ignora a distinção objetivo-subjetivo no percepto dos sentimentos?

Além disso, descobri mais tarde que a distinção externo-interno me parece mais adequada do que a distinção objetivo-subjetivo. A palavra subjetivo apresenta, além da minha definição, o caráter de caracterizar o indivíduo como aquele que se sente como possuidor de uma "tendência para reduzir toda a existência ao sujeito" $\left(\right.$ Ferreira, 1986, p. 1620) ${ }^{8}$. Ao contrário a palavra objetivo caracterizaria também a tendência a ".. existirem normas objetivas, de validade geral” (Ferreira, 1986, p. 1208) ${ }^{9}$. Esta maneira de utilizar o significado das palavras portuguesas vale também para a tradução em várias outras línguas, como o inglês e o francês. Portanto, é melhor caracterizá-las através da primeira distinção: externointerno.

Entretanto, o termo estado subjetivo é bastante utilizado, constando atualmente da subdivisão de psicologia experimental, parte das áreas de conhecimento de ciências humanas. Minha conclusão é empregar dois pares de vocábulos como sinônimas: estado externo ou objetivo e estado interno ou subjetivo.

\section{A Proposição de Cinco Escalões de Percepto}

As dúvidas que apresentei acima com relação ao número de escalões inferiores ao estado bipartido, as evidências da escola gestaltista da totalidade de Munique para quem as emoções ocupavam todo o campo do percepto, e as leituras de artigos e livros de percepção, no momento até 1980 , me certificaram quanto a proposição da existência de cinco escalões de percepto. São, indo da Gestalt única até a maior divisão das gestalten: (A) estado total, (B) estado bipartido, (C) estado supramodal,

\footnotetext{
${ }^{8}$ No termo subjetivismo.

${ }^{9}$ A citação refere-se ao vocábulo objetivismo.
} 


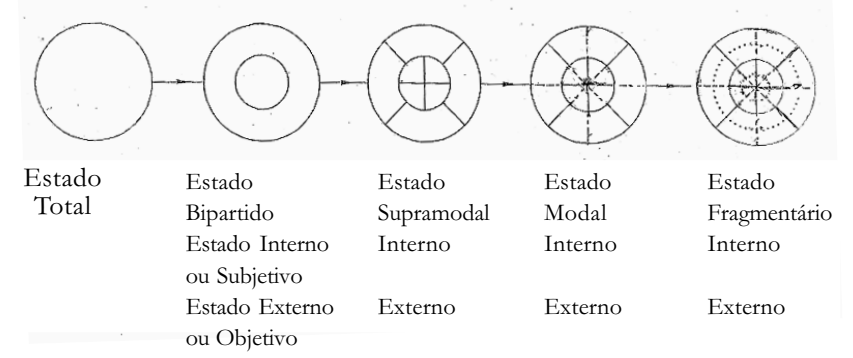

Figura 1. Representação esquemática dos escalões de percepto.

(D) estado modal e (E) estado fragmentário (veja na Figura $1)^{10}$. Descendo a partir do estado bipartido, todos os quatro estados apresentam uma parte externa e uma interna.

Os cinco escalões que acabamos de arrolar vão dos estados amplos até os restritos. O par de adjetivos amplorestrito refere-se ao tamanho dos acontecimentos percebidos. O adjetivo amplo se refere a grandes espaços dos perceptos; o adjetivo restrito se refere a pequenos espaços dos perceptos. Assim no escalão de estado total o espaço é o mais amplo; no escalão de estado fragmentário os perceptos são os mais restritos. Nos escalões intermedários, a amplidão diminui ou a restrição aumenta. Há uma semelhança com Werner (1948/1961). Entretanto, para Werner os acontecimentos vão de conteúdos sincréticos até discretos, retratando o desenvolvimento. No meu caso, os cinco estados são apenas maneiras de perceber. Os seres humanos preferem o estado supramodal e a repartição estado bipartido interno ou subjetivo. Portanto, a direção dos estados amplos para os restritos não obedece a nenhuma direção além da estrutural.

Muda com a passagem de um estado a outro o seu conteúdo? A não ser a atitude do percebedor, o conteúdo não se altera.

Atitude é conhecida, hoje em dia, como um fator de origem cultural ou social com influência na predisposição relativamente duradoura em relação a determinadas pessoas; levam o sujeito a reagir não como as pessoas realmente são mas como pensa que elas são. Um exemplo seria a atitude negativa que alguns indivíduos apresentam em São Paulo ante pessoas de origem nordestina. Essa atitude socialé um conceito posterior na psicologia a noções de percepção que foram introduzidos na mesma ciência

\footnotetext{
${ }^{10}$ Agradeço a confecção da Figura 1 ao engenheiro Faustino Máximo da Silva.

em fins do século XIX. Esse primeiro conceito de atitude - atitude perceptiva - é uma orientação temporária, que dura minutos ou horas, ao contrário da atitude social que pode durar anos. É esse conceito primeiro de atitude que será utilizado no presente texto (Cabral, 1979; Doron \& Parot, 1991).

Vejamos rapidamente dois experimentos realizados há bastante tempo, um por Benussi no começo do século XX e outro por Brunswik na década de 1940, e que empregam o conceito de atitude perceptiva. Em 1904, Vittorio Benussi, um psicólogo da linha de qualidade gestaltista ou Gestaltqualität de von Ehrenfels e Meinong, e que trabalhava na época em Graz na Áustria, realizou um experimento sobre a ilusão geométrica de MüllerLyer - duas linhas paralelas com dois tipos de flechas em suas pontas, o primeiro tipo com as duas flechas para dentro e o outro com as duas flechas para fora (veja a Figura 2). O único sujeito de Benussi em inúmeras apresentações tinha de perceber a figura ora na atitude comum de todo ora na atitude de isolamento das partes. A ilusão era mais forte na primeira atitude do que na segunda. A atitude de isolamento das partes leva à diminuição de uma ilusão bem característica (Engelmann, 2002; Woodworth, 1938).

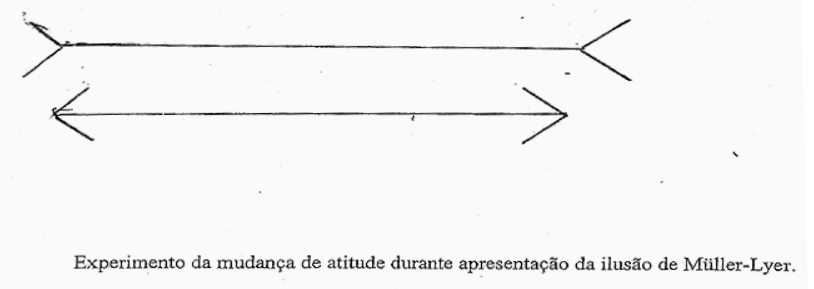

Figura 2. Estimulação no experimento de Benussi (1904).

Egon Brunswik (1944), um psicólogo húngaro que passou uma parte de sua vida nos Estados Unidos, programou um experimento com situações da vida natural das pessoas. Pediu a uma aluna de pós-graduação que julgasse o tamanho de 93 objetos que ela encontrava por acaso em sua locomoção diária através da casa, do laboratório, das ruas e do campus universitário. No total eram 180 situações experimentais naturais e que aconteceram num período de quatro semanas. Em cada um dos julgamentos de tamanho, a moça deveria assumir, entre outras atitudes, uma atitude perceptiva realista-ingênua 
ou uma atitude de pintor. Como instruções para levar o sujeito a assumir uma atitude realista-ingênua, Brunswik disse-lhe o seguinte:

Dê suas estimações na base de sua primeira impressão dos tamanhos dos objetos em questão. Você precisa considerar os tamanhos das 'coisas' como vistas na atitude comum de sua vida diária... Não se deixe influenciar pelos seus conhecimentos abstratos acerca do tamanho dos objetos em questão, ou da memória deles, ou da ótica, etc. ${ }^{11}$

$\mathrm{Na}$ atitude chamada de pintor ou perceptiva analitica disse-lhe:

Tente analisar perceptivamente ou desintegrar a cena de uma maneira tal que um pintor deveria ser capaz de desenhar um retrato perspectivamente correto... Relacione seu julgamento como a uma vara imaginária situada num plano frontal, a um metro de distância de seus olhos. ${ }^{12}$

Os julgamentos foram distribuídos aleatoriamente numa ou noutra atitude. As duas atitudes representariam, para Brunswik, dois polos principais de intenção da percepção: se o objeto fora visto dentro do quadro tridimensional - distal — ou se fora visto como se apresentando numa tela colocada num cavalete a um metro de distância - proximal. Os resultados mostram correlações diferentes entre os tamanhos reais dos objetos e os perceptos nas duas atitudes. As correlações são perto de 1,00 nas atitudes distais e perto de 0,70 nas atitudes proximais.

Nesses exemplos duas atitudes perceptivas são utilizadas. Por que não poderiam ser usadas cinco? As diferenças entre elas são as mesmas que nos experimentos de Benussi e de Brunswik.

A seguir, vamos colocar as características e as evidências empíricas dos cinco estados.

\section{Estado total}

São estados momentâneos de consciência nos quais o percepto todo aparece como uma gestalt una.

\footnotetext{
${ }^{11}$ Minha tradução de Brunswik (1944, p. 4): “(1) Naive perceptual attitude [b]: Give your estimates on the basis of your first impression of the sizes of the objects in question. You should consider the sizes of the "things" as seen in the ordinary attitude of daily life (not projective sizes relative to your location.) Do not let yourself be influenced by your abstract knowledge about, or memory of, the sizes of the objects in question, or of optics, etc." Os trechos traduzidos estão sublinhados. ${ }^{12}$ Minha tradução de Brunswik (1944, p. 4): “(2) Analytical perceptual attitude [p]: Try to perceptually analyze or to disintegrate the scene, in the way a painter would have to see it in order to be able to draw a perspectively correct picture - in other words, try to estimate visual angles, or the relative sizes of the objects as they could be measured on your retina or on a photograph with the camera set up where you are standing. Relate your judgment to an imaginary meter stick in a frontal plane at one meter distance from the eye." Os trechos traduzidos estão sublinhados.
}

O núcleo da idéia do todo surgiu na escola de Graz sob influência de von Ehrenfels, na virada do século XIX ao XX. Sob a direção de Meinong, Benussi realizou experimentos nos quais há sempre, em todo momento, uma consciência total. Cornelius foi, por sua vez, influenciado von Ehrenfels e Meinong. Em 1897, Cornelius escreveu que os sentimentos são qualidades de todo. Seu discípulo, Krueger chamava de sentimentos a totalidade, sendo a totalidade idêntica àquilo que denomino estado total.

O sentimento muda de momento para momento, mas invade a consciência como um todo. Entretanto, a única maneira de conhecer esse sentimento é tomar a consciência como estado total. É uma experiência vivida. Entretanto, essa totalidade acaba rapidamente em experimentos de psicologia, no qual se toma uma atitude analítica. Os experimentos realizados em Leipzig depois da Primeira Guerra Mundial até 1940, assim como investigações mais recentes retratam o estado total (Engelmann, 2002; Hentschel, Smith \& Draguns, 1986; Krueger, 1926/1953a, 1937/1953b; Sander, 1930/1973, 1937/1962; Volkelt, 1934/1962).

O que acontece com indivíduos que passam por problemas de meditação? Pelo que se sabe há vários milênios de anos, o ponto final é um estado de consciência no qual não há diferença entre a própria pessoa e os objetos, ou nos termos da teoria atual, não há diferença entre a parte externa e a parte interna. Seria, à primeira vista, também um estado total. Nesse estado total, não é apenas a divisão que desaparece, mas também a preocupação cotidiana com tudo que se passa no ambiente. "A experiência apareceria por ser a consciência por si só - pura, silenciosa e vazia de todos os objetos fenomênicos"13.

Ao contrário dos outros escalões e da situação descrita por Krueger, nunca passei pessoalmente por meditação. Entretanto, Austin (1998) me assegura que cinco por cento de tempo dos seres humanos são gastos em períodos de consciência blanks em inglês ou važios, ainda que esses períodos são necessários para contrabalançar inúmeras ações. Seria um repouso fisiológico, mas que nos seres humanos, e penso em outros animais que são conscientes, caracteriza estados totais. Nas meditações Zen há métodos para aumentar os períodos de vazio. Nesses períodos, há também uma claridade dessa consciência.

Um outro tipo de meditação é a transcendental de Maharishi. No momento de aquisição do estado de samadhi, os meditadores ou sujeitos ${ }^{14}$ transcendem a consciência mais

\footnotetext{
13 "This experience would appear to be one of consciousness alone by itself - pure, silent, and empty of all "phenomenal' objects" (Shear e Jevning, 1999, p. 194). A tradução é minha.

${ }^{14}$ Os inúmeros meditadores de cada tipo de meditação foram considerados sujeitos por Shear e Jevning, ainda que não haja, em geral, a precisão requerida nos estudos experimentais.
} 
comum e alcançam um modo de ser de tranqüilidade, em que novamente não existe a divisão entre observador e observado.

Austin lembra que em estudos a respeito da meditação Zen, o termo em inglês para traduzir o japonês muchin foi ausência de mente. A ausência de mente ou consciência não ocorre durante as meditações. Pelo contrário, a consciência seria bem caracterizada. Entretanto, seria um estado total e, além disso, livre das preocupações (Austin, 1998; Crook, 1980; Shear \& Jevning, 1999).

\section{Estado bipartido}

$\mathrm{O}$ indivíduo encontra uma bipartição da pele percebida, de tal maneira que apenas dois estados podem ocorrer: o estado externo ou objetivo fora da pele percebida e o estado interno ou subjetivo dentro da pele percebida. Durante muito tempo escrevi sobre aquilo que denominei de estados subjetivos. Foi a partir desta definição que surgiu a presente teoria dos estados de percepto na década de 1980.

Evidências sobre estados externos são os menos citados. Além de Cattell (1957), pode-se mencionar o livro de Katz (1935), publicado primeiro em alemão em 1930 e depois traduzido para o inglês; estudos do Ganzfeld ou campo total no qual a estimulação percebida por um observador é completamente homogênea (Koffka, 1935); repetição dos experimentos com luzes coloridas (Hochberg, Triebel \& Seaman, 1951). Eduardo Legal (2002) que tinha sido meu doutorando, apresentou uma tese que utiliza relatos verbais de estados externos, de maneira semelhante àquela que apresentei com relação a estados internos.

Sobre estudos de estados subjetivos ou internos apresentaram-se nestas últimas décadas diversas pesquisas. É um dos estados preferenciais para percepção consciente. Pode-se exemplificar com o excelente estudo de Carroll Izard (1972). Além disso, há pesquisas realizadas por Wessman e Ricks (1966), Davitz (1969), Fleeson e Cantor (1995), Schimmack e Diener (1997), etc. De Rivera (1984), Scherer, Wallbot e Summerfield (1986) e Lewis e Haviland (1993), em sua seção III Processos básicos na emoção, organizaram publicações nas quais se demonstra o estado interno. No Brasil, além do meu livro Os estados subjetivos (Engelmann, 1978), há artigos publicados por Souza, Camacho e Tavares (1985), Engelmann (1986a, 1986b, 1987), Pereira e Engelmann (1993), Alves e Engelmann (2000).

\section{Estado supramodal}

Estado supramodal, externo ou interno, é o outro estado preferido. Tanto a parte externa quanto a interna seria dividida em trechos menores. Esses trechos menores, no entanto, teriam contribuição visual, auditiva, olfativa e outros na parte externa e proprioceptiva, interoceptiva e outros na parte interna. Além disso, os perceptos se referem a acontecimentos tridimensionais na parte externa, incluindo trechos que correspondem a objetos que não enviam estimulação. Apesar disso os perceptos incluem essa parte sem estimulação. Recebe o nome de parte amodal.

Psicólogos trabalham com visão, audição, olfato, dor, etc., esquecendo que a maneira normal de apresentar perceptos é, muitas vezes, ignorar a modalidade ou sensação. "A maneira com que os sistemas se interrelacionam representa um papel fundamental. É a regra, ao invés da exceção"15, disse Lawrence E. Marks em 1978. Apesar de ser um forte defensor do requerimento de que a informação inicial deve ser integrada, adota o termo de percepção multimodal, influenciado pela maneira majoritária de abordar a observação psicológica. Creio que sua posição sobre a percepção é a correta. Entretanto, o termo deve ser supramodal e não multimodal (Marks, 1978a).

Há algumas características que podem ser percebidas numa única modalidade. Nesse caso, a consciência perceptiva se apresentará no quarto estado, o modal. Mas, apesar disso, creio que normalmente a percepção humana é supramodal.

Marks (1978b) relatou cinco maneiras de compreender esse problema: (a) a doutrina da informação equivalente, de acordo com a qual os diferentes sentidos informam sobre as mesmas características dos objetos externos; (b) a doutrina dos atributos e qualidades análogos, de acordo com a qual haveria atributos das várias sensações supra-sensoriais; (c) a doutrina das propriedades psicofisicas comuns, de acordo com a qual os muito diferentes sentidos apresentam a mesma propriedade psicofísica; (d) a doutrina das correspondências neurais, de acordo com a qual mecanismos neurofisiológicos idênticos ou semelhantes se traduziriam por processo neurais iguais; e (e) a doutrina da unidade dos sentidos, de acordo com a qual os diferentes sentidos seriam interpretados como evolução de uma única sensibilidade primitiva. Além disso, essa última doutrina incorpora as quatro anteriores. Foi associada a pesquisas de Heinz Werner (1934, 1948/1961). Ela tem, em parte, a aprovação de Lawrence Marks e também a minha.

Ao que parece, a primeira citação longa desta possibilidade é devida a Aristóteles, no século IV A.C. Após apresentar as cinco possibilidades modais chamadas de clássicas — visão, audição, olfação, gustação e tato —

\footnotetext{
15 “... the way sensory systems interrelate, plays a fundamental role, and that is the rule, rather than the exception." (Marks, 1978a, p. 322). A tradução é minha e o trecho grifado é meu.
} 
descreve mais uma sensação, o sensus communis. Não é mais um tipo de modalidade, mas a natureza comum aos cinco anteriores (Aristóteles, trad.1947; Ross, 1923/1949).

Os estados supramodais externos apresentam o tipo de percepção mais comum. Apesar disso o número de experimentos, em comparação ao grande número de perceptos modais, é muito reduzido. Os mais citados sobre estado supramodal externo são de von Hornbostel (1927/1955), de Werner (1934), de Marks (1978b) e de Walk e Pick (1981). Os principais estudos sobre estado supramodal interno são os de Mason (1961), de Davitz (1969), de Shields (1984) e de Nieuwenhuyse, Offenberg e Frijda (1987).

\section{Estado modal}

São os perceptos externos ou internos nos quais a modalidade ou o tipo de sensação constituem uma das diferenciações. A maioria dos estudos atuais de percepção se qualificam nesse tipo de estado modal.

Estudos sobre o estado modal são os mais comuns dentro da psicologia da percepção. Como exemplo, podemos citar o capítulo de Dodwell (1975), os livros de Rock (1975) e de Gibson (1979) para os casos de visão, o capítulo de Jones (1978) para os casos de audição e de Kenshalo (1978) para percepção térmica, isto no caso de estados modais externos. No caso de estados modais internos mencionaremos o capítulo de Kenshalo (1978), escrevendo sobre a cinestesia. Os capítulos de Sternbach (1978) e de Chapman (1978), além do livro de Melzack e Wall (1988), colocam a dor como estado modal. Em português temos os livros de Simões e Tiedemann (1985) e de Biasoli-Alves e Da Silva (1990).

\section{Estado fragmentário}

Estados fragmentários é o nome que dei aos experimentos do início da psicologia experimental que analisava a consciência em elementos ou sensações, pequenas partes que se atingia durante a introspecção clássica. Entretanto, elemento deve ser guardado como oposto de gestalt, enquanto maneiras de abordar a observação. Sensação apresenta o duplo sentido de uma parte da consciência e de uma parte fisiológica. Além disso, sensação é também sinônimo de modalidade. Por isso, criei um termo para as menores partes: fragmentos.

Koffka (1924) foi um dos iniciadores da escola gestáltica de Berlim. Entretanto, sua formação incluía passagem por laboratórios de introspecção. Em seu artigo, Koffka mostra a inanição levada por experimentos desse tipo. Os resultados eram afastados da vida diária. Entretanto, como eram feitos por pessoas sob a orientação de psicólogos, evidentemente caracterizavam uma situação sui generis.

Em 1879, quando Wundt inaugurou o seu laboratório em Leipzig, um dos objetivos do estudo da consciência era chegar aos "elementos" mentais. Wundt escreve sobre dois métodos de observação da consciência: (1) a autoobservação ou Selbstbeobachtung e (2) a percepção interna ou innere Wabrnehmung. O primeiro método, no qual a consciência introspectiva descreve a lembrança recente do objeto, não capta a percepção real mas a memória. Por isso, Wundt rejeita esse tipo de introspecção, que realmente seria retrospecção. Ao contrário, a percepção interna seria a percepção presente de um objeto num tempo mínimo. $\mathrm{O}$ relato verbal seria tão rápido que não encontraria eventos de memória curta. Em todo caso, o observador passaria por uma prática com o propósito de realçar uma observação rápida atentiva. Esse dado pode ser científico, se for repetido em tempos imediatamente posteriores. A seguir, pela abstração de diversas percepções internas de um sujeito experimental olhando um objeto, constroem-se os "elementos" psíquicos. A dificuldade desses experimentos resultou em estudos de laboratório limitados a julgamentos de tamanho, intensidade e duração dos estímulos físicos (Danziger, 1980; Wundt, 1905).

A introspecção para Titchener era algo diferente da de Wundt, ainda que tenha sido discípulo de Wundt e introdutor e tradutor de muitos dos seus tratados para o inglês. Titchener aprendera filosofia e fisiologia em sua terra natal, a Grã-Bretanha. A introspecção para ele, e para a maioria dos ingleses, era o que Wundt chamou de auto-observação. $\mathrm{O}$ introspeccionista realmente tinha de realizar o experimento através da memória curta. Essa era a melhor maneira de captar a consciência. O observador era treinado de maneira a captar os "elementos" e não realizar o erro de estímulo, isto é, confundir a "sensação" com características da estimulação (Boring, 1921/1963; Titchener, 1912). As "sensações" eram, para Titchener, os constituintes básicos e fundamentais da consciência. A sua teoria era o sensacionalismo, teoria que advoga o conhecimento baseado unicamente em "sensações" (Danziger, 1980; Titchener, 1909/1973, 1913; Tweney \& Yachanin, 1980).

É difícil, hoje em dia, ter uma idéia sobre a justeza científica dos experimentos da época. Em todo caso, os sujeitos experimentais eram sérios e procuravam analisar suas percepções conscientes nos “elementos” formadores. Por isso, é justo haver um estado mais retalhado que o modal, o fragmentário. Os sujeitos dos experimentos deviam passar para a introspecção após longo treino. O número de sujeitos, de outro lado, era pequeno. 
Os números iniciais das revistas Philosophische Studien, Archiv der gesamte Psychologie e American Journal of Psychology, estão preenchidos por artigos desta tendência psicológica. As "sensações" visuais, auditivas, táteis, térmicas, gustativas e olfativas referem-se a fragmentos externos. As "sensações" proprioceptivas e interoceptivas referem-se a fragmentos internos. Os sentimentos referem-se tanto a fragmentos internos quanto externos. Revisões mais recentes dão se no livro de Beebe-Center (1932/1965), nos capítulos 10, 19, 20, 21 e 22 do tratado de Woodworth (1938) e na parte sobre o feeling do livro de Magda Arnold (Arnold, 1960).

\section{Ânimos: Estados Bipartidos Internos ou de Outro Lado Estados Totais}

Parti da posição que as emoções, sentimentos, afetos e, além disso, outros estados não-emocionais semelhantes eram na sua maioria perceptos bipartidos internos ou subjetivos (Engelmann, 1978). Koffka julga que as emoções conscientes são na maioria organizações do Ego. Essa era maneira com que eram observadas por muitos outros gestaltistas da escola de Berlim e mesmo um discípulo de Krueger. De outro lado, essas mesmas emoções seriam totalidades em termos da maioria dos psicólogos gestaltistas de Leipzig. Portanto, do meu ponto de vista seriam estados totais (Koffka, 1935; Krueger, 1937, 1953b; Sander, 1930/1973, 1937/1962).

Quem teria a razão? Pensei longamente no assunto e cheguei à conclusão que ambos. Normalmente, as emoções-sentimentos são estados bipartidos internos, mas em certas situações seriam estados totais. E como denominar às vezes o estado bipartido interno e às vezes o estado total? Deveria ser um termo novo. Animos, ou moods em inglês, seriam estados que são emocionais, como angry (com raiva), sad (triste), e também não emocionais, como serious (sério), tired (cansado), de acordo com Nowlis (1965). Passei a denominá-los também de estados de ânimos. Entretanto, ânimo é um estado disjuntivo.

Conceito disjuntivo é aquele que é definido por dois ou mais atributos, que não são iguais (Bruner, Goodnow \& Austin, 1956). As ciências são construídas por conceitos conjuntivos, aqueles cuja definição é uma só. Entretanto, há situações na ciência em que os conceitos são disjuntivos. Por exemplo, o conceito de substâncias capazes de causar alergia num ser humano pode ser pó de giz ou pelo de gato ou comer camarão. Do mesmo modo, podemos definir estado de ânimo como aquele que é estado bipartido interno ou estado total.

\section{As Mudanças nos Escalões de Percepto}

Um observador está sentado numa poltrona perto da janela e olhando para dentro da sala. Ele percebe sempre a mesma estimulação. Na parte mais próxima há uma mesa longa com livros espalhados por cima. Mais longe, uma estante está encostada na parede, também com livros, e uma mesa com quatro cadeiras, duas de cada lado. A mesa e as cadeiras funcionam como local de almoço ou de jantar. No entanto, no momento está vazia. Além disso, o observador pode olhar para as paredes da sala.

Como verificar a teoria dos cinco escalões de percepto nesta situação? O observador pode estar no estado total. Para ele há uma ansiedade quanto a um exame que ele deverá fazer dentro de três horas na escola. A ansiedade é forte e invade não apenas sua pessoa mas também tudo que se encontra fora dele. Evidentemente, tudo que se encontra fora dele é aquilo que forma parte da sua consciência. Ignoram-se acontecimentos que ocorrem dentro da sala, mas que não são capazes de lhe apresentar perceptos. Com o tempo, o grau de ansiedade diminui. O observador pode mudar agora para um estado bipartido. Sente ansiedade dentro dele, mas por fora percebe um dia claro, mas frio. Seu estado bipartido externo é apenas dia claro e frio. Agora muda-se de novo seu escalão de percepto. Passa para o estado supramodal. Percebe os vários objetos que se encontram na mesa longa e perto dele. Há dois livros, um novo e o outro bem antigo, que ele precisa olhar antes do exame. Esses livros estão na frente e percebe que possuem a forma tridimensional. $\mathrm{O}$ livro novo apresenta uma capa lustrosa e um cheiro característico. O outro apresenta o cheiro dos papeis velhos e sua superfície é rugosa. Percebe os dois livros não apenas como vistos, mas também como tatuados. Dentro dele, percebe reações corporais internas difusas. O observador pode tornar-se uma pessoa mais atenta. Vê a superfície da capa do livro novo, mas somente a parte mostrada. Capta o seu olfato. Ele está num estado modal. Pode, também, mudar para o estado fragmentário. Vê, não a capa em que está escrito Física, mas pontos vermelhos e brancos. Como uma parte do livro está à sombra, percebe, tanto o vermelho quanto o branco como mais claros ou como mais escuros.

É importante no exemplo acima, como disse antes, que diante de uma situação relativamente a mesma, o observador pode mudar o seu escalão. A mudança de escalão é fruto de uma alteração da atitude perceptiva. Como se muda, não se sabe, pelo menos conscientemente.

É possível apresentar dois ou mais escalões de percepto ao mesmo tempo? Creio que não. Essas ocorrências apresentam uma grande similaridade com aquelas que se apresentam no percepto visual quando se mostra uma única estimulação com duas possíveis gestalten na visão de figuras. São exemplos clássicos as visões de figura e 
(A) Figura Ambígua: figura e fundo

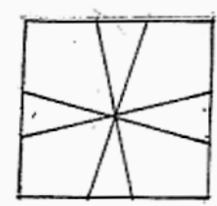

(B) Figura Ambígua: cubo projetado numa superfície bidimensional

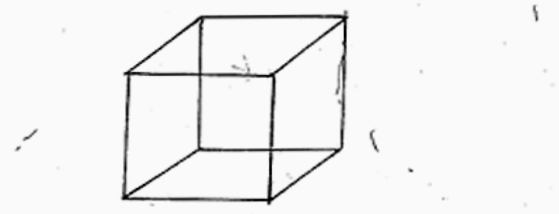

(A) Tanto a cruz pode ser vista como figura comop o X pode ser visto como figura. Entretanto, a cruz e o X não podem ser vistas como figuras ao mesmo tempo.

(B) $O$ ponto da direita central é visto na frente ou o ponto da esquerda central é visto na frente. Entretanto, as duas visões são imcompatíveis no mesmo instante.

Figura 3. Visões das figuras.

fundo ou as visões de um cubo projetado numa superfície bidimensional (veja as Figuras 3 A e B). Nesse caso, a consciência, num determinado momento, é de uma ou de outra, mas nunca a visão simultânea das duas (Koffka, 1935; Wertheimer, 1923/1938). Essa consciência única deve apresentar-se também no caso dos cinco escalões de percepto.

O que ocorre no caso de dois, ou mais, estados de percepto que apresentam o mesmo nome por causa de um conceito disjuntivo? Não mostram nenhuma diferença por causa desse nome. Inclusive, mantive no exemplo citado, a ansiedade como ocorrendo como estado total e como estado bipartido interno. São escalões diferentes e, portanto, não podem coexistir.

\section{A Base Neural e a Consciência-mediata-de-outros}

A teoria dos escalões de percepto lida com acontecimentos dentro da consciência-mediata-de-outros. Esta é, de acordo com a teoria geral de sistemas, uma parte do nível de organismo. Há processos neurais que apresentam uma influência nos processos conscientes. Entretanto, não se conhece bem todos os mecanismos.

De modo geral, há uma parte do cérebro mais relacionada com processos que se conectam com os órgãos sensoriais externos ou internos ao corpo. Há uma parte do cérebro mais relacionada com atividade emocional. Essa última, chamada de límbica por MacLean (1975), se basearia em porções mais antigas do cérebro do que as porções sensoriais. Portanto, haveria no cérebro uma parte emocional e uma parte sensorial. Em artigo mais recente, LeDoux (1995) indica uma série de dúvidas quanto à anatomia do sistema límbico e quanto à existência de uma parte emocional tal como a descreveu MacLean. LeDoux acredita que sob o nome de emocões há uma série de conceitos que talvez não devam ser unidos sob uma organização neurológica única.

Entretanto, ao descrever os referidos por indicadores da consciência na consciência-mediata-de-outros, sejam de origem sensorial sejam de origem emocional, o produto é uno. Não há uma diferença significativa entre os dois. Essa dupla repartição fisiológica — talvez seja bem maior do que dois - daria origem a um único fato consciente na neurofisiologia de Cytowic. A clássica divisão entre sensações ou cognições, de um lado, e afetos ou sentimentos ou emoções, de outro, como partes da consciência-mediata não cabe aqui, pela falta de dados empíricos que a comprovem. Por exemplo, os conteúdos de consciência indicados pelos relatos verbais vejo uma mesa ou sinto dor no dente molar superior ou acho o dia extremamente frio ou sinto raiva do meu chefe de seção cabem todos entre os mesmos perceptos. A repartição é entre determinantes neurais dos acontecimentos da consciência-mediata e não a divisão da própria consciência-mediata (Cytowic, 1996; Engelmann, 1997b).

\section{Dúvidas para Prosseguir}

É a teoria que apresentamos sobre escalões de percepto um esquema fechado? De um lado, sim. Entretanto, se a considerarmos uma parte da consciência-mediata-de-outros, então há muito assunto a ser discutido. As imagens, entendidas como tão próximas de perceptos, não seriam igualmente submetidas aos mesmos escalões? E, finalmente, haveria uma divisão também de pensamentos e/ou de volições?

Diversos autores acreditam, pelo menos no caso do ser humano, que existe uma consciência chamada por muitos de primária e, sobre ela, uma consciência chamada também por muitos de refletiva (Edelman, 1992; Farthing, 1992; Sommerhoff, 1990). Sem discutir as bases fisiológicas ou psicológicas dessa divisão, que aliás pode ser perfeitamente correta, acho que quando se tem consciência de sua consciência a situação é bem diferente daquela em que não se a tem. A consciência de sua consciência é uma situação na qual se acha um "eupuro" e uma aparência, ligados num gestalt. Com ou sem a presença do "eu puro", o restante da consciência será quase o mesmo. Será quase o mesmo, porque o estado total durante a meditação não pode ocorrer. Uma das características do ápice da meditação é a ausência completa de qualquer divisão. A presença de um "eu puro" 
quebra essa divisão. É por isso que tenho minhas dúvidas se mantenho a meditação como percepto ou deixo-a para o caso geral da consciência.

Há muitos estudos sobre as imagens, inclusive sobre o relacionamento entre essas imagens e as partes neurológicas. Durante muito tempo, houve uma discussão sobre se o característico era a imagem como forma de percepto ou pelo contrário sobre sua natureza espacial abstrata. Ao que parece, hoje em dia, ambos os ponto de vista são corretos. Nesse caso, a teoria dos escalões de percepto poderia ser algo válida apenas no primeiro caso, na forma como percepto (Farah, 1995; Tye, 1991).

Os pensamentos devem ser ativos. Entretanto, também podem ser passivos e nesse caso subordinados a um esquema semelhante ao desse texto ${ }^{16} . \mathrm{E}$ as volições? São apenas ativas. A classificação hierárquica dos perceptos parece ser apenas um dos campos que pode ser estudado.

\section{Conclusão}

Esse artigo, além de mostrar a teoria dos cinco escalões de percepto, apresenta uma forma histórica de meus pensamentos. Em 1962 elaborei o estudo de emoções. Como já era na época gestaltista, posição em que agora continuo após passados quarenta anos, meu interesse era estudar a consciência emocional. A consciência emocional apresentava como característica ser percebida como interna ao indivíduo, mas não apresentar além disso nenhuma localização. Entretanto, havia outros estados que realmente não poderiam ser chamados de emocionais, como sentir cansaço ou sentir calor, e que apresentavam quanto ao resto as mesmas características do que as emocionais. Achei melhor criar o conceito de estado subjetivo.

Havia, ao mesmo tempo, alguns estudos que retratavam perceptos internos, porém localizados. Esses estudos retratavam freqüentemente também emoções. A consciência, portanto, podia ser vista como possuindo dois escalões nesse caso: 1) o estado subjetivo, superior; e 2) o percepto interno, inferior.

De outro lado, havia nas várias línguas nomes tais como está frio, está úmido. Esses nomes correspondem a estados que são percebidos por fora da pele do corpo, mas que não se pode localizar quanto ao resto. Novo conceito devia ser criado - estado objetivo.

Que relação haveria entre os estados objetivos e os perceptos? Pensei no assunto, reli muita pesquisa realizada

\footnotetext{
${ }^{16}$ A velha classificação de Descartes (1649/1989) é realmente válida. Os conteúdos de consciência podem ser ativos, quando o ser humano os produz, e passivos, quando se apresentam à consciência (Engelmann, 1997a).

e achei que deveria propor os escalões de percepto, indo da única parte do todo até o número maior de partes do todo, isto é, de cima para baixo. No momento são cinco: 1) estado total; 2) estado bipartido, outrora estado objetivo-subjetivo; 3) estado supramodal; 4) estado modal e 5) estado fragmentário. As pessoas poderiam estar num desses estados ou em outro, mas, de maneira semelhante às atitudes perceptivas, não poderiam estar ao mesmo tempo em mais de um estado. Dois estados são preferenciais: o estado supramodal, externo ou interno, e o estado bipartido interno ou subjetivo.

Essa a conclusão atual. Será a conclusão definitiva? Além de perceptos na consciência, há imagens, pensamentos, volições e outros. Pode ser que me aventure em estudar a sua relação com os escalões de percepto.

\section{Referências}

Alves, J. M. \& Engelmann, A. (2000). Relatos verbais maternos sobre palavras de estados subjetivos que seus filhos pequenos entendem e/ ou falam. Humanitas, 16(1/2), 75-85.

Aristote (Aristóteles) (1947) De l'âme (J. Tricot, Trad. do grego antigo). Paris: J. Vrin.

Arnold, M. (1960). Emotion and personality. New York: Columbia University Press.

Ash, M. G. (1995). Gestalt psychology in German culture 1890-1967. New York: Cambridge University Press.

Austin, J. H. (1998). Zen and the brain: Toward an understanding of meditation and consciousness. Cambridge, MA: MIT.

Azevedo, F. F. dos S. (1950). Dicionário analógico da língua portuguesa (Idéias afins). São Paulo: Editora Nacional.

Beebe-Center, J. G. (1965). The psychology of pleasantness and unpleasantness. New York: Russell \& Russell. (Original publicado em 1932)

Bertalanffy, L. von (1968). General system theory (Ed. rev.). New York: George Braziller.

Bertalanffy, L. von (1975). The history and development of general system theory. Em L. von Bertalanffy (Org.), Perspectives on general system theory (pp. 149-169). (Original publicado em 1972)

Biasoli-Alves, Z. M. M. \& Da Silva, J. A. (Orgs.) (1990). Percepção: Múltiplas visões. Ribeirão Preto, SP: Universidade de São Paulo, Campus de Ribeirão Preto.

Boring, E. G. (1963). The stimulus-error. Em E. G. Boring (Org.), History, psychology, and science (pp. 255-273). New York: John Wiley. (Original publicado em 1921)

Bruner, J. S., Goodnow, J. J. \& Austin, G. A. (1956). A study of thinking. New York: John Wiley.

Brunswik, E. (1944). Distal focussing of perception: Size-constancy in a representative sample of situations. Psychological Monographs, 56(1, $\mathrm{N}^{\circ}$ completo 254).

Cabral, A. (1979). Dicionário de psicologia e psicanálise (2 $2^{\mathrm{a}}$ ed.). Rio de Janeiro: Expressão e cultura.

Cattell, R. B. (1957). Personality and motivation structure and measurement. Yonkerson-Hudson, NY: World Book.

Chapman, C. R. (1978). The hurtful world: Pathological pain and its control. Em E. C. Carterette \& M. P. Friedman (Orgs.), Handbook of perception: Vol. VTB. Feeling and burting (pp. 264-301). New York: Academic Press.

Claparède, E. (1928). Feelings and emotions. Em M. L. Reymert (Org.), Feelings and emotions: The Wittenberg symposium (pp. 124-139). Worcester, MA: Clark University Press. 
Crook, J. H. (1980). The evolution of human consciousness. Oxford, UK: Clarendon.

Cytowic, R. E. (1996). The neurological side of neuropsychology. Cambridge, MA: MIT.

Danziger, K. (1980). The history of introspection reconsidered. Journal of the History of the Behaviorial Sciences, 16, 241-262.

Davitz, J. R. (1969). The language of emotion. New York: Academic Press.

Descartes, R. (1989). Les passions de l'âme. Em F. Alquié (Org.), Oevres philosophiques. Tome III (pp. 941-1103). Paris: Bordas. (Original publicado em 1649)

Dodwell, P. C. (1975). Pattern and object perception. Em E. C. Cartertette \& M. P. Friedman (Orgs.), Handbook of perception: Vol. V. Seeing (pp. 267299). New York: Academic Press.

Doron, R. \& Parot, F. (Orgs.) (1991). Dictionnaire de psychologie. Paris: P.U.F.

Edelman, G. M. (1992). Bright air, brilliant fire. New York Basic Books.

Engelmann, A. (1978). Os estados subjetivos: Uma tentativa de classificação de seus relatos verbais. São Paulo: Ática.

Engelmann, A. (1982). A psicologia, um ramo da biologia - e as ciências sociais também. Ciências e Cultura, 34, 1154-1163.

Engelmann, A. (1985). Comportamento verbal e relato verbal. Psicologia, 11(1), 1-6.

Engelmann, A. (1986a). LEP - Uma lista, de origem brasileira, para medir a presença de estados de ânimo no momento em que está sendo respondida. Ciência e Cultura, 38, 121-146.

Engelmann, A. (1986b). Contribuições recentes à investigação de estados subjetivos. Ciência e Cultura, 38, 1021-1026.

Engelmann, A. (1987). Percepción de estados de ánimo en sujetos brasileños. Revista Latinoamericana de Psicologia, 19(3), 319-336.

Engelmann, A. (1997a). Dois tipos de consciência: A busca da autenticidade. Psicologia USP, 8(2), 25-67.

Engelmann, A. (1997b). Principais modos de pesquisar a consciênciamediata-de-outros. Psicologia USP, 8 (2), 251-274.

Engelmann, A. (1998). Ciência natural e consciência. Psicologia: Reflexão e Crítica, 11, 273-280.

Engelmann, A. (2001). O meu-mundo e o resto-do-mundo. Psicologia: Reflexão e Crítica, 14, 211-223.

Engelmann, A. (2002). A psicologia da Gestalt e a ciência empírica contemporânea. Psicologia: Teoria e Pesquisa, 18, 1-16.

Farah, M. J. (1995). The neural bases of mental imagery. Em M. S. Gazzaniga (Org.), The cognitive neurosciences (pp. 963-975). Cambridge, MA: MIT.

Farthing, G. W. (1992). The psychology of consciousness. Englewood Cliffs, NJ: Prentice-Hall.

Ferreira, A. B. de H. (1986). Novo dicionário da língua portuguesa (2a ed.). Rio de Janeiro: Nova Fronteira.

Ferreira, A. B. de H. (1999). Novo dicionário da língua portuguesa (3 $\left.{ }^{\mathrm{a}} \mathrm{ed}.\right)$. Rio de Janeiro: Nova Fronteira.

Fleeson, W. \& Cantor, N. (1995). Goal relevance and the affective experience of daily life. Motivation and Emotion, 19, 25-57.

Gibson, J. J. (1979). The ecological approach to visual perception. Boston: Houghton Mifflin.

Hentschel, U., Smith, G. \& Draguns, J. G. (1986). Subliminal perception, microgenesis, and personality. Em U. Hentschel, G. Smith \& J. G. Draguns (Orgs.), The roots of perception (pp. 3-36). Amsterdam: Elsevier.

Hochberg, J. E., Triebel, W. \& Seaman, G. (1951) Color adaptation under conditions of homogeneous visual stimulation (Ganzfeld). Journal of Experimental Psychology, 41, 153-159.

Hornbostel, E. M. von (1955). The unity of the senses. Em W. D. Ellis (Org.), A source book of gestalt psychology (pp. 210-216) E. Koffka \& W. Vinton, Trads.). London: Routledge \& Kegan Paul. (Original publicado em 1927)

Izard, C. E. (1972). Patterns of emotions. New York: Academic Press.

James, W. (1950). The principles of psychology. New York: Dover. (Original publicado em 1890)

James, W. (1967). What is an emotion? Em K. Dunlap (Org.), The emotions (pp. 11-30). New York: Hafner. (Original publicado em 1884)
Jantsch, E. (1980). The self-organizing universe. Oxford, UK: Pergamon.

Jones, M. R. (1978). Auditory patterns: Studies in the perception of structure. Em E. C. Carterette \& M. P. Friedman (Orgs.), Handbook of perception: Vol. VTII. Perceptual coding (pp. 255-288). New York: Academic Press.

Katz, D. (1935). The world of colour (R. B. MacLeod \& C. W. Fox, Trads.). London: Kegan Paul, Trench, Trubner \& Co. (Original publicado em 1911; 2a. ed. 1930)

Kenshalo Sr., D. R. (1978). Biophysics and psychophysics of feeling. Em E. C. Carterette \& M. P. Friedman (Orgs.), Handbook of perception: Vol. VIB. Feeling and burting (pp. 30-74). New York: Academic Press.

Koffka, K. (1924). Introspection and the method of psychology. British Journal of Psychology, 15, 149-161.

Koffka, K. (1935). Principles of Gestalt psychology. London: Routledge \& Kegan Paul.

Köhler, K. (1938a). The place of value in a world of facts. New York: Liveright.

Köhler, K. (1938b). Physical Gestalten: A source book of Gestalt psychology. Em W. D. Ellis (Org.), Physical Gestalten (pp. 17-54) (W. D. Ellis, Trad.). London: Routledge \& Kegan Paul. (Original publicado em 1920)

Krueger, F. (1953a). Über psychische Ganzheit. Em E. Heus (Org.), Felix Krueger - Zur Philosophie und Psychologie der Ganzheit (pp. 33-124). Berlim: Springer- Verlag. (Original publicado em 1926)

Krueger, F. (1953b). Das Wesen der Gefühle. Em E. Heus (Org.), Felix Krueger - Zur Philosophie und Psychologie der Ganzheit (pp. 195-221). Berlim: Springer-Verlag. (Original publicado em 1937)

Lange, C. G. (1967). The emotions. (I. A. Haupt, Trad.). Em K. Dunlap (Org.), The emotions (pp. 33-90). New York: Hafner. (Original publicado em 1885)

LeDoux, J. E. (1995). In search of an emotional system in the brain: Leaping from fear to emotion and consciousness. Em M. S. Gazzaniga (Org.), The cognitive neurosciences (pp. 1049-1061). Cambridge, MA: MIT.

Legal, E. J. (2002). Levantamento dos realtos verbais dos esclaões bipartidos externos. Tese de Doutorado não-publicada, Instituto de Psicologia, Universidade de São Paulo. São Paulo, SP.

Lewis, M. \& Haviland, J. M. (Orgs.) (1993). Handbook of emotions. New York: Guilford.

MacLean, P. D. (1975). Sensory and perceptive factors in emotional functions of the triune brain. Em L. Levi (Org.), Emotions.: Their parameters and measurement (pp. 71-92). New York: Raven Press.

Marks, L. E . (1978a). Multimodal perception. Em E. C. Carterette \& M. P. Friedman (Orgs.), Handbook of perception: Vol. VIII. Perceptual coding (pp. 321-339). New York: Academic Press.

Marks, L. E. (1978b). The unity of the senses. New York: Academic Press.

Mason, R. E. (1961). Internal perception and bodily functioning. New York: International Universities Press.

Melzack, R. \& Wall, P. (1988). The challenge of pain (Ed. rev.). London: Penguin.

Miller, J. G. (1978). Living systems. New York: McGraw-Hill.

Miller, J. G. \& Miller, J. L. (1982). The earth as a system. Behavioral Science, 27, 302-322.

Natsoulas, T. (1988). Is any state of consciousness self-intimating? Journal of Mind and Behavior, 9, 167-204.

Natsoulas, T. (1991). Introspecting and consciousness: A response to Howe. New Ideas in Psychology, 9 (1), 45-50.

Nieuwenhuyse, B., Offenberg, L. \& Frijda, N. H. (1987). Subjective emotion and reported body experience. Motivation and Emotion, 11, 169-182.

Nowlis, V. (1965). Research with the Mood Adjective Check List. Em S. S. Tomkins \& C. E. Izard (Orgs.), Affect, cognition, and personality (pp. 352389). London: Tavistock.

Pereira, C. A. A. \& Engelmann, A. (1993). Um estudo da qualidade de vida universitária no trabalho entre docentes da UFRJ. Arquivos Brasileiros de Psicologia, 45, 12-48.

Prado e Silva, A. (Org.) (1970). Novo dicionário brasileiro Melhoramentos ilustrado: Vol. IV. São Paulo: Melhoramentos.

Rapoport, A. (1968). General systems theory. Em D. L. Sills (Org.), International encyclopedia of the social sciences. (Vol. 15, pp. 452-458). New York: Macmillan \& Free Press. 
Rivera, J. de (Org.) (1984). The analysis of emotional experience. American Behavioral Scientist, 27, 675-832.

Rock, I. (1975). An introduction to perception. New York: Macmillan.

Ross, W. D. (1949). Aristotle. London: Methuen. (Original publicado em 1923)

Sander, F. (1962). Zur neueren Gefühlslehre. Em F. Sander \& H. Volkelt (Orgs.), Ganzheitspsychologie (pp. 125-146). Munique: C. H. Beck'sche Verlagsbuchhandlung. (Original publicado em 1937)

Sander, F. (1973). Structure, totality of experience, and Gestalt. Em C. Murchison (Org.), Psychologies of 1930 (pp. 188-204) (S. Langer, Trad.). Worcester, MA: Clark University. (Original publicado em 1930)

Scherer, K. R., Wallbott, H. G. \& Sommerfield, A. B. (Orgs.) (1986). Experiencing emotion. Cambridge, Inglaterra: Cambridge University Press.

Schimmack, U. \& Diener, E. (1997). Affect intensity: Separating intensity and frequency in repeatedly measured affect. Journal of Personality and Social Psychology, 73, 1313-1329.

Shear, J. \& Jevning, R. (1999). Pure consciousness: Scientific exploration of meditation techniques. Em F. J.Varela \& J. Shear (Orgs.), The view from within: First-person approaches to the study of consciousness (pp. 189-209). San Diego, CA: Imprint Academic.

Shields, S. A. (1984). Reports of bodily change in anxiety, sadness, and anger. Motivation and Emotion, 8, 1-21.

Simões, E. A. Q. \& Tiedemann, K. B. (1985). Psicologia da percep̧̣ão. São Paulo: E.P.U.

Sommerhoff, G. (1990). Life, brain and consciousness. Amsterdam: Elsevier.

Souza, M. R. C., Camacho, C. \& Tavares, S. (1985). Alterações nos estados subjetivos de pessoas idosas em decorrência da audição musical. Psicologia, 11, 53-62.

Spitzer, C. (1956). Dicionário analógico da lingua portuguêsa (5 $5^{\mathrm{a}}$ ed.). Porto Alegre: Globo.

Sternbach, R. A. (1978). Psychological dimensions and perceptual analyses, including pathologies of pain. Em E. C. Carterette \& M. P. Friedman (Orgs.), Handbook of perception: Vol. VIB. Feeling and burting (pp. 231-261). New York: Academic Press.
Titchener, E. B. (1912). The schema of introspection. American Journal of Psychology, 23, 485-508.

Titchener, E. B. (1913). A primer of psychology (Ed. rev.). New York: Macmillan.

Titchener, E. B. (1973). Lectures on the experimental psychology of the thoughtprocesses. New York: Arno Press. (Original publicado em 1909)

Tweney, R. D. \& Yachanin, S. A. (1980). Titchener's Wundt. Em W. G. Bringmann \& R. D. Tweney (Orgs.), Wundt studies (pp. 380-395). Toronto: C. J. Hogrefe.

Tye, M. (1991). The imagery debate. Cambridge, MA: MIT.

Volkelt, H. (1962). Grundbegriffe der Ganzheitspsychologie. Em F. Sander \& H. Volkelt (Orgs.), Ganzheitspsychologie (pp. 31-65). Munique: C. H. Beck'sche Verlagsbuchhandlung. (Original publicado em 1934)

Walk, R. D. \& Pick, H. L., Jr. (Orgs.) (1981). Intersensory perception and sensory integration. New York: Plenum.

Werner, H. (1934). L'unité des sens. Journal de Psychologie, 31, 190-205.

Werner, H. (1961). Comparative psychology of mental development. New York: Science Editions. (Original publicado na $2^{\mathrm{a}}$ ed. em 1948)

Wertheimer, M. (1938). Laws of organization in perceptual forms. (W. D. Ellis, Trad.). Em W. D. Ellis (Org.), A source book of Gestalt Psychology (pp. 71-88). London: Routledge \& Kegan Paul. (Original publicado em 1923)

Wessman, A. E. \& Ricks, D. F. (1966). Mood and personality. New York: Holt, Rinehart and Winston.

Whitehead, A. N. (1985). Science and the modern world. London: Free Association Books. (Original publicado em 1926)

Woodworth, R. S. (1938). Experimental Psychology. New York: Henry Holt. Wundt, W. (1905). Grundriss der Psychologie (7 $7^{\mathrm{a}}$ ed.). Leipzig: Wilhelm Engelmann.

Sobre o autor

Arno Engelmann é Professor Titular em Psicologia no IP/USP, Pesquisador do Departamento de Psicologia Experimental do Instituto de Psicologia da USP. 